\title{
Voice-Based Agents as Personified Things: Assimilation and Accommodation as Equilibration of Doubt
}

\author{
Katrin Etzrodt ${ }^{1}$ (D) and Sven Engesser ${ }^{1}$ (i) \\ 1 Science and Technology Communication, Technical University Dresden, Dresden, Germany
}

\section{Abstract}

We aim to investigate the nature of doubt regarding voice-based agents by referring to Piaget's ontological object-subject classification "thing" and "person," its associated equilibration processes, and influential factors of the situation, the user, and the agent. In two online surveys, we asked 853 and 435 participants, ranging from 17 to 65 years of age, to assess Alexa and the Google Assistant. We discovered that only some people viewed voice-based agents as mere things, whereas the majority classified them into personified things. However, their classification is fragile and depends basically on the imputation of subject-like attributes of agency and mind to the voice-based agents, increased by a dyadic using situation, previous regular interactions, a younger age, and an introverted personality of the user. We discuss these results in a broader context.

Keywords: artificial agents, classification, ontology, social actor, hybrids

\section{Introduction}

When it comes to being social, people are built to make the conservative error:

When in doubt, treat it as human. (Reeves \& Nass, 1996, p. 22)

In 2011, Apple launched Siri, the first commercialized voice-based agent (VBA). More VBAs have followed rapidly and have entered the habitats of people (Newman, 2018), the

CONTACT Katrin Etzrodt (iD · Science and Technology Communication • Technical University Dresden • katrin.etzrodt@tu-dresden.de 
most popular being the Google Assistant (launched in 2012), Microsoft's Cortana (2013), and Amazon's Alexa (2014). However, neither users nor scientists have yet been able to completely grasp the nature of these VBAs (Guzman, 2019). Thus, clarifying the fundamental question of 'what is it?' has become one of the main research issues within humanmachine communication (A. Edwards et al., 2020). In this paper, we will explore the nature of these VBAs by investigating how they are categorized as objects, subjects, or in-between. We aim at making the classification of commercial VBAs and the associated processes of "equilibration" (Piaget, 1970/1974) accessible for empirical research.

Both CASA and Social Presence Theory argue that VBAs are what Reeves \& Nass (1996, p. 22) describe as objects of doubt. Research under the CASA paradigm (Nass et al., 1994), postulating that computers are social actors, has provided multifaceted evidence that people exhibit diverse social reactions toward various technological artifacts such as traditional media, computers, avatars, or robots. Social Presence Theory (Short et al., 1976) assumes that these reactions are caused by the perception of mediated social entities as being present (Lombard et al., 2017), or by the failure to recognize those entities as artificial (K. M. Lee, 2004), and specifically as "non-human" (Latour, 2005). Although even marginal social cues can trigger social reactions and the feeling of presence (e.g., Reeves \& Nass, 1996), anthropological similarity can further enhance them (e.g., Appel et al., 2012; Horstmann et al., 2018). In particular, voices are notably powerful indicators of social presence (Reeves \& Nass, 1996) and being able to talk can be an indicator for being alive (Turkle, 1984/2005, p. 48).

Although a large body of research in the past 30 years has investigated the consequences of this doubt (e.g., the activation of social heuristics), we know very little about the doubt itself. It is still unclear toward "whom" or "what" (Gunkel, 2020, p. 54) people react when they are interacting with (artificially intelligent) machines. The various terminologies used to describe them, such as "evocative objects" (Turkle, 1984/2005), "quasi-objects" or "hybrids" (Latour, 1991/1995), "epistemic things" (Knorr-Cetina, 2001), "non-humans" (Latour, 2005), "subject objects" (Suchman, 2011), or "social things" (Guzman, 2015) illustrate the difficulty of capturing their essence. Although definitions differ considerably, common to all terms is the reference to ambiguous entities possessing both object qualities and subject qualities, whose unique combination creates new qualities beyond the sum of its parts (Roßler, 2008). In the paper at hand, we aim at investigating the categorization of these doubtful objects.

For this purpose, we will argue that the doubt arises from an irritated ontological object-subject classification by referring to the epistemologist Piaget (1970/1974). We will outline how people resolve the irritation through specific equilibration processes by assigning the irritating object to an existing scheme or modifying these schemes gradually.

The second part of the paper is dedicated to influences on this classification. Research on artificial agents indicates that attributes of the situation (A. Edwards et al., 2019; Purington et al., 2017), of the users (Epley et al., 2007; E. J. Lee et al., 2000; Woods et al., 2007), and of the agents themselves (e.g., Nass \& Moon, 2000; Reeves \& Nass, 1996) may be relevant.

Based on an empirical approach, we designed a scale for the classification, assessed situational, individual, and technological influences in an online survey, and validated the findings with a second sample. By investigating the degree to which people classify a VBA as social actor, ranging between thing and person, and the identification of influences we 
intend to advance the concept of human-machine communication and contribute to the CASA paradigm.

\section{Classification of Voice-Based Agents}

Voice-based agents like Siri, Alexa, and the Google Assistant are a subtype of artificial social agents, with an operating system based on artificial intelligence and natural language processing using a disembodied voice emanating from a device (e.g., smartphone, loudspeaker box) to communicate with the users and execute their tasks. They are still a reasonably new technology, meaning that people lack exhaustive previous experience with this unique conversational interface (Guzman, 2015; Krummheuer, 2015). However, there are signs for human-machine agent interaction scripts (Gambino et al., 2020), suggesting a gradual object-subject classification of artificial agents. Thus, we ask to which degree people classify VBAs into the object-subject classification (RQ1).

\section{Voice-Based Agents as Objects of Doubt}

Referring to Piaget's studies on epistemology (1970/1974), we assume the most fundamental way of gaining knowledge about a new object is figuring out if it is part of the "psychomorph" or the "physicomorph" scheme, which are diametrical poles of the same ontological classification. Turkle (1984/2005, p. 34) referred to these poles as "psychological" and "physical." Gunkel (2020, p. 54) arrived at a similar conclusion by referring to Derrida's distinction of "who" and "what." The psychomorph scheme ("who") is defined by subjects, which are living beings, equipped with capacities like thinking or feeling, and the potential of agency (Piaget, 1970/1974, p. 48). Thus, it is an analog to the scheme "other persons" (Gunkel, 2020, p. 54), and used "to understand people and animals" (Turkle, 1984/2005, p. 34). In contrast, the physicomorph scheme ("what") is defined by inorganic, non-living objects, which are sufficiently comprehensible in terms of precise, logical-mathematical categories, and deterministic causal laws (Geser, 1989, p. 233). That is, it is an analog to the scheme "things [that] are mere instruments or tools" (Gunkel, 2020, p. 54), and "used to understand things" (Turkle, 1984/2005, p. 34). While the physicomorph scheme (hereinafter referred to as thing theme) results from empirical experience (e.g., physical perception and movement), the psychomorph scheme (hereinafter referred to as person theme) originates in the introspective experience of a subjectivity (Piaget, 1970/1974). This theoretical approach is related to the impossible verification of subjectivity (Gunkel, 2020; Turing, 1950) or agency (Krummheuer, 2015), as well as to the imputation of mental states to objects (Premack \& Woodruff, 1978) and the gradual assignment of personhood (Hubbard, 2011), as discussed prior in Etzrodt (2021).

Despite the growing ability to distinguish between psychomorph and physicomorph due to the individual's development and its constant confrontation with the environment (Piaget, 1970/1974; Turkle, 1984/2005), some objects remain a challenge. Between things and persons, there exists a wide range of objects (e.g., plants, animals, or artificial entities) that can be regarded as objects of doubt. Recent empirical research confirms the doubtful nature of various artificial social agents: Guzman (2015) noted in her qualitative interviews a constantly shifting use of the pronouns "she" and "it" when people talked about the VBA 
Siri. It seemed that Guzman's respondents were torn between the association of a person and a thing, which she traced back to the interviewees' focus of attention. If their "attention turns away from Siri the voice or Siri the image to Siri the program, Siri again becomes a thing" (Guzman, 2015, p. 195); thus, she concludes, people "recognize certain characteristics of humans and machines within them" (p. 257). A. Edwards (2018) found a similar inconsistency, when she asked her participants to choose two out of the three entities (social robot, human, and primate), that had more in common in relation to the third. Although, participants combined humans and primates in opposition to social robots, based on robots being artificial and non-living things, some coupled robots and humans in reference to their (assumed) resemblance in embodiment, intellect, and behavior, and the capability to interact socially through talking and understanding.

\section{Voice-Based Agents as Objects of Equilibration}

Once the classification of an object is in doubt, the irritation has to be resolved. People need to decide if machines are "mere things ... or someone who matters . . . or something altogether different that is situated in between the one and the other" (Gunkel, 2020, p. 56). Piaget (1970/1974) refers to this as equilibration-a balancing and self-regulating process, which is achieved through assimilation or accommodation (Figure 1).

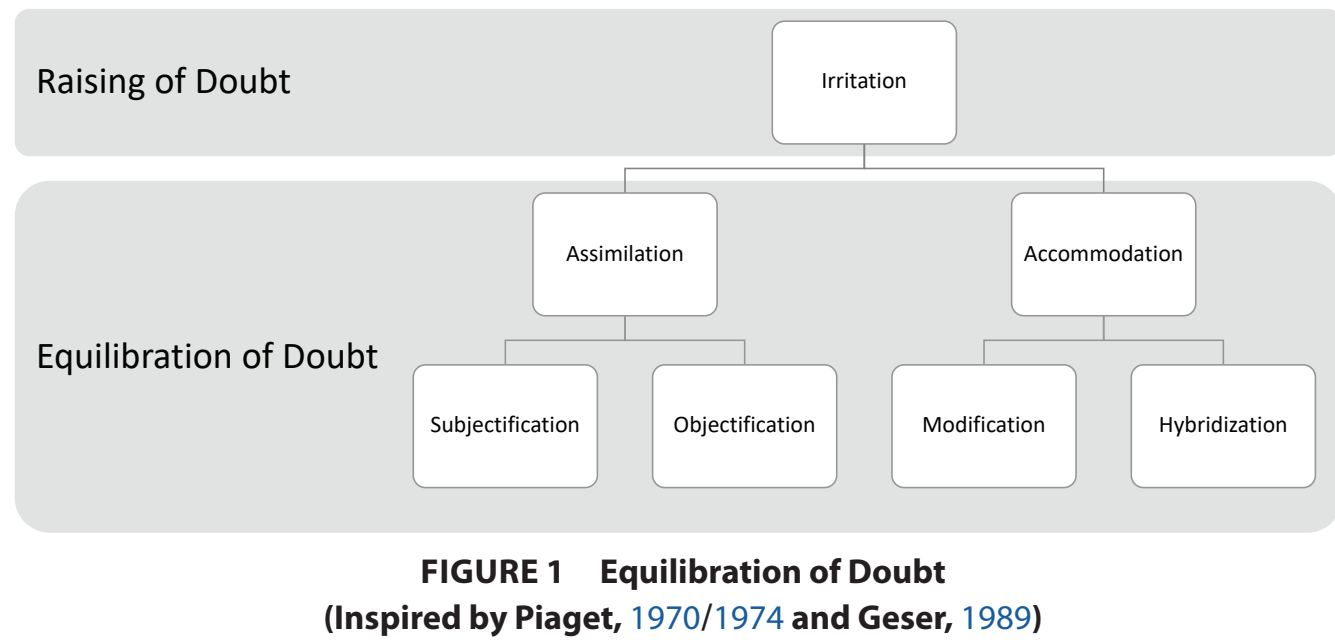

Assimilation is the assignment of an irritating object, such as the VBA, to an existing scheme: the thing scheme (objectification) or the person scheme (subjectification). As a result, people overestimate either the VBA's objecthood or subjecthood. Particularly for Siri, Guzman (2015) found that some people explicitly described it as an entity, while others viewed it as a device. Similar associations were found by Purington and colleagues (2017) in the user comments about Alexa (Amazon Echo). They demonstrated that, although the objectifying pronoun "it" was used by the majority of the authors, some favored the personifying pronoun "she." The preference of objectification is confirmed for social robots by A. Edwards (2018), where more than half of the respondents regarded social robots as things in contrast to living and natural subjects such as humans or apes. Therefore, we 
formulate the hypothesis (H1): VBAs are assimilated more often to the thing scheme than to the person scheme.

Accommodation refers either to the modification of an existing scheme or to the creation of a new one (Piaget, 1970/1974). Regarding the modification of the object-subject classification, the thing scheme can be modified by adding person attributes or the person scheme can be enriched with thing attributes. Apart from that, people may build a hybrid scheme, featuring a more or less balanced combination of attributes from things and persons (hybridization). While modification draws on existing heuristics and changes them slightly, hybridization requires the active acquisition and construction of completely new heuristics.

Research on VBAs implies accommodation: In addition to the "spectrum from fully human to fully machine," Guzman (2015, p. 227) identified an "overlap in the middle" concerning the ontology of Siri, as a result of a reconfigured "understanding of humans and machines to the degree that we now share characteristics" (p. 257). Purington and colleagues (2017) found a mixed use of the pronouns "she" and "it" for Alexa in the same user comment. Furthermore, some user reactions suggest accommodation through the simultaneous activation of social and non-social scripts, such as inappropriate, rude, or insensitive social behavior toward artificial agents: For example, people abuse social robots (Broadbent, 2017), and direct bullying and sexual harassment toward VBAs like Alexa (Cercas Curry \& Rieser, 2018).

\section{Influences on the Classification of Voice-Based Agents}

Although social reactions toward computers are fundamentally human, exist in all groups, and occur even in the case of weak social cues (Reeves \& Nass, 1996), there is evidence that object-subject classification varies due to factors at the levels of situation, user, and agent. Thus, we ask to what extent do factors at the levels of the situation, the user, and the agent influence the object-subject classification of VBAs (RQ2)?

\section{Attributes of the Situation}

The ontological classification of machines can differ between various situational interactions and social contexts. A. Edwards and colleagues (2019) found that a positive expectancy violation during an initial interaction with a social robot reinforces the feeling of social presence and reduces uncertainty. Leite and colleagues (2013) suggested a change in relationship through prolonged interaction. Furthermore, personification increased when Alexa was embedded in multi-person households such as families (Lopatovska \& Williams, 2018; Purington et al., 2017). Against this backdrop, we assume that previous interactions with VBAs affect the classification (H2) and its use in the presence of others increases the classification's preference for the person scheme $(\mathrm{H} 3)$.

\section{Attributes of the User}

Age appears to be a major influence on classification. Children are known to attribute subject status to objects in general (Piaget, 1970/1974) and artificial agents (Epley et al., 2007; 
Turkle, 1984/2005) more strongly than adults do. Apart from that, users' attributes seem to affect the perceived attributes of the agents rather than their classification. In this context, age in general affects perceived similarities between a participant's and a robot's personality traits (Woods et al., 2007). In contrast, the impact of gender appears inconsistent. Gender neither affects the perception of a social presence for synthesized voices (K. M. Lee \& Nass, 2005), nor the evaluation of flattery behavior of the VBA (E. J. Lee, 2008). However, the attribution of personality to robots may be gender-specific (Woods et al., 2007); and matching genders of the user and the VBA alters social reactions (E. J. Lee et al., 2000). Besides, personality traits of the user have been crucial for research, reflecting differences between individuals as well as parallels in interaction in general. Although research did not find effects of the user's personality on the perception of social presence, matching personalities of user and VBA may influence perceived characteristics-regarding the trait "extravertintrovert" (Nass \& Lee, 2001), and similarity_regarding the trait "neuroticism-emotional stability" (Woods et al., 2007). Closely related to personality is a person's affinity for technology (Attig et al., 2017), which is particularly noticeable regarding the novelty of VBAs.

\section{Attributes of the Agent}

The VBA's conversational mode exhibits subject-likeness, involving expressed effective and meaningful behavior and the imputation of agency and mind. However, it is still unclear to what extent they are relevant for the object-subject classification.

Agency as expression of effective behavior. Due to the recently increased capabilities of machines to mimic natural human behavior their genuine agency is conveyed more strongly (Guzman, 2018). VBAs can directly answer users, communicate with and control other smart objects in their environment (e.g., switching lights on and off), collect and present information from the internet, activate apps, or initiate purchases. Thus, in the context of VBAs, the term agency refers to an effect, originating from interaction with the environment and other beings, which may be interpreted as behavior similar to humans (e.g., A. Edwards, 2018). Within the framework of social interaction theory, this effect refers to the ability of interdependence (Simmel, 1908) and orientation (Weber, 1922) toward the behavior of others-thus, they are affecting others and are affected by others. The most basic indicator for interdependence between VBAs and users is the VBAs' expression of receptiveness to vocal commands. For instance, Alexa lights up a blue ring on the Amazon Echo and a blue line on the Amazon Echo Show to indicate it is "listening." To demonstrate the ability of orientation the VBA needs to express attentiveness in the first place (Biocca et al., 2003). Alexa does this by additionally turning a brighter light toward the direction of the sound source in most Echo devices. The feeling of receptivity increases the perception of sociality-including that of computers (Burgoon et al., 1999) and agency in general (Appel et al., 2012; Guadagno et al., 2007). However, it is unclear to what degree the VBA's classification is altered if their behavior is perceived as effective. 
Mind as expression of meaningful behavior. The human-like voice and the use of language are expressions of meaningful behavior, which is closely linked to consciousness (Reichertz, 2014), and a theory of mind (Epley et al., 2007; Premack \& Woodruff, 1978). Thus, the language- and voice-based subjectivity transcends the ability to interact effectively by adding meaning to its actions. Meaningful behavior is crucial for orientation in any social interaction and based on mutual understanding, on similarity in thinking and/or feeling (to some degree), and the assumption of intentional actions. That is, before an orientation toward the actions of others is possible, these actions must be understood based on one's own and the anticipated other's experiences within a shared (natural or social) world (Schütz, 1974). In particular, the conversational mode of VBAs incorporates such specific assumptions of similarity in thinking and feeling to a certain degree: First, the use of words of a certain language, and that VBAs understand these words, refers to a specific shared social world between users and VBAs. Second, by referring to themselves as "I," VBAs suggest that they are person-like, self-conscious entities, which operate according to the same rules as their human users.

Furthermore, the meaning of actions is closely related to the assumption of intentionality, in contrast to accidental actions or for purely physical reasons (Simmel, 1908). The simplest complex of intentionality that can be attributed to an action are motives (Schütz, 1974). According to Schütz, it is sufficient to put oneself in a typical position with typical motives and plans. Personality constitutes the origin of these typical motives, attitudes, and mindsets of persons as subjects. It contains both the assumption about behavior that is based on typical human nature, typical decisions, reactions, or feelings and on ways in which individuals differ from each other (Buss, 2008). Therefore, a perceived personality suggests a subject who chose to act in a specific manner, but theoretically could have responded in a different way (Higgins \& Scholer, 2008). As a result, if personality is attributed to a VBA its actions may be no longer viewed as random-regardless of whether they were programmed to imitate intention or whether they are behaving intentionally by nature. Research confirms the attribution of personality traits to synthetic voices (e.g., C. Edwards et al., 2019; Ray, 1986) and very specific personalities to the commercial VBAs Alexa and the Google Assistant (Garcia et al., 2018). However, it is uncertain whether the quantity or quality of perceived personality traits of the VBA alter the object-subject classification. Previous CASA research has concentrated on the quality such as the personality trait "extraversion" in interpersonal interactions and uncovered extraverted voices are generally perceived as more socially present (e.g., K. M. Lee, 2004; Nass \& Lee, 2001; Nass \& Moon, 2000). Although extraversion may be relevant for social reactions toward VBAs, it is unanswered if extraversion or other personality traits or that personality traits are attributed in the first place are relevant for their classification.

\section{Research Questions and Hypotheses}

An overview of the relevant variables, research questions, and hypothesized influences can be found in the theoretical model (see Figure 2). 


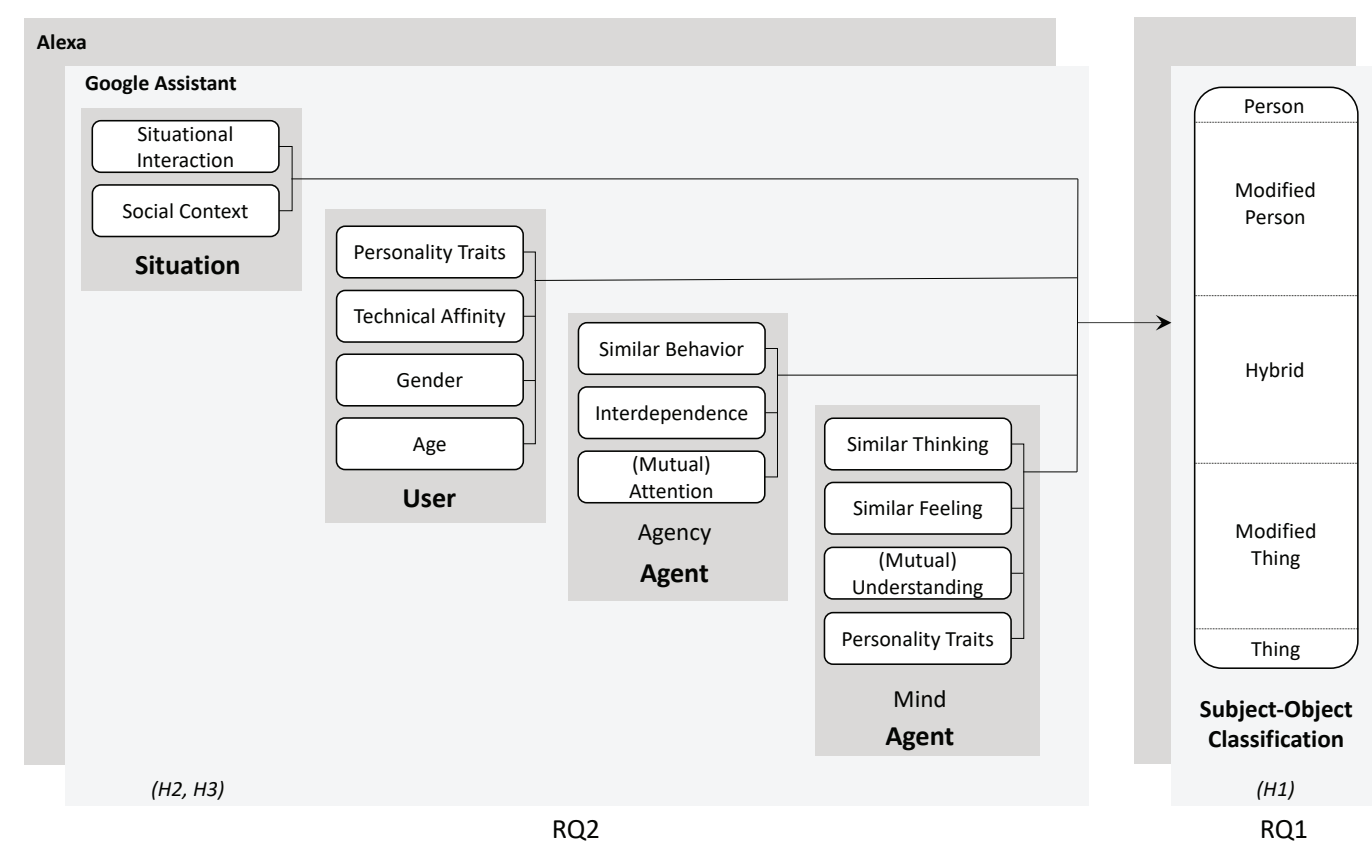

FIGURE 2 Theoretical Factor Model

\section{Method}

\section{Sample}

In late 2018, we conducted an online survey with a demonstrational design $(\mathrm{N}=853)$ among all students of a large German university, recruited via the university's student mailing list (response rate of 2.6\%) and randomly assigned to either the VBA Alexa (Amazon Echo) or the Google Assistant (Google Home). Participants had a mean age of 24, ranging from 17 to 50 years, $52 \%$ of whom were male, $76 \%$ were undergraduates, and $23 \%$ graduates. The sample was (on a 6-point scale) above average creative $(\mathrm{M}=3.67, \mathrm{SD}=1.00)$, conscientious $(\mathrm{M}=3.46, \mathrm{SD}=0.86)$, and emotionally stable $(\mathrm{M}=3.2, \mathrm{SD}=0.93)$, as well as moderately agreeable $(\mathrm{M}=3.1, \mathrm{SD}=0.86)$ and extraverted $(\mathrm{M}=3.1, \mathrm{SD}=1.09)$. It expressed an affinity for technology above average $(\mathrm{M}=4.01, \mathrm{SD}=1.20,6$-point scale).

Most of the participants already knew the names Alexa (96\%), and the Google Assistant $(71 \%)$ in general, and $84 \%$ knew their assigned VBA. Although one third owned the assigned Google Assistant (33\%), only some possessed Alexa (7\%). The primary sources of knowing Alexa were indirect ones: advertisement (43\%) and contact through other people (24\%), which however, were also important for Google Assistant (17\% advertisement, 12\% other people). Other indirect sources were non-fictive media (Alexa: 16\%, Google Assistant: 7\%) and rarely fictive media (Alexa: 6\%, Google Assistant: 1\%). If the participants had used their assigned VBA prior to the survey's demonstrational interaction, most of them had used it primarily alone $(60 \%)$ and moderately frequent $(\mathrm{M}=3.3, \mathrm{SD}=1.45,5$-point scale).

According to its average age the student sample belonged to a cohort widely labelled as Generation Z, which differs from the previous cohort (commonly labeled as Millennials) 
in political, economic, and social factors (Dimock, 2019; Singh, 2014). Regarding these differences of generations and the classification's development during aging, the study was repeated with an older sample (Millennials) - all employees of the same university, recruited via the university's staff mailing list (response rate of 6.2\%) - to validate the findings and specify cross-generational effects. The staff sample $(\mathrm{N}=435)$ was, on average, 10 years older (with a mean age of 33, from 18 to 65 years), 65\% were graduates, 26\% were undergraduates, and $3 \%$ had a doctoral degree. Participants were slightly more conscientious $(M=3.71$, $\mathrm{SD}=0.78)$ and had less affinity for technology $(\mathrm{M}=3.96, \mathrm{SD}=1.20)$, however, their prior experiences with the assigned VBA resembled those of the student sample.

\section{Procedure}

Although both assistants' German voices were female, they differed in their characters, the way they were advertised, and their manufacturing companies' image. To distinguish between possible variations caused by the mentioned differences and general classifications of VBAs, one group of participants assessed Alexa, another the Google Assistant. To get impressions as close as possible to the true perception of the two VBAs, we chose a demonstrational design by simulating interactions with pre-recorded videos with the original answers of the voice-based loudspeaker variants of the Google Assistant or Alexa to predefined questions in German (Table A1 in the study's OSF repository). Before the simulated interaction, participants reported their previous experiences with various VBAs (including the assigned VBA) and typical usage situations. During the simulated interaction, they activated four videos of the VBA's answer one after the other by clicking on the question. After the interaction, they classified the VBA and assessed perceived attributes.

Questions for the VBAs were selected that had been advertised previously by Amazon or Google as preferable interaction features (e.g., in commercials or on the website), and that had the potential to exhibit personality characteristics of the VBA. If a VBA provided multiple answers to the same question, we randomly selected one. Because people form their impressions within the first few seconds of contact with a voice (Ray, 1986), the video sequence for each simulated interaction had a duration between 7 and 17 seconds. The videos can be obtained from this study's OSF repository.

\section{Measures}

Object-Subject Classification. To examine the object-subject classification, we drew on the diametrical relation of the thing scheme and the person scheme described above and asked participants: "What would you say, is Alexa [or the Google Assistant] rather like a thing (object) to you or rather like a person (subject)?" Because "person" refers to the status "personhood," it can be assumed with Hubbard (2011) that it is a gradual assignment, whose highest degree is represented by the term "person." To address the continuum between the schemes we used a 100-point scale, consisting of the two poles "thing (object)" and "person (subject)."

As discussed in Etzrodt (2021), the broad-scale allowed intuitive answers-independent of the participant's ability to verbalize the classification (Turkle, 1984/2005, p. 48). It also allowed to detect minor forms of accommodation and to distinguish between modification 
and hybridization (see Figure 3). As described by the author, classification as the result of assimilation into the thing or the person scheme refers to the absence of any previous accommodation, indicated on the scale by the ratings of 1 or 101. Thus, VBAs are added to the existing scheme (thing or person), but the scheme itself does neither get in conflict with the other nor does it change. Classification as a result of accommodation depends on pre-existing structures (Piaget, 1974, p. 34), referring to a change or reaffirmation of the categories' borders (Turkle, 2005). Hence, Etzrodt (2021) concludes, the accommodated classification is measured by a weak or strong merging of the thing and the person scheme, implied if people were distancing from one of the poles on the scale. A weak merging is represented by ratings close to one of the schemes (2-33 and 67-100), indicating the modification of a dominant scheme by implementing elements of the other. A strong merging is represented by ratings near the scale's center (34-66), indicating a hybridization with a more or less balanced reunion of both schemes. To determine how sophisticated the equilibration process was, we asked how confident participants were in their classification on a 5-point scale (Etzrodt, 2021).

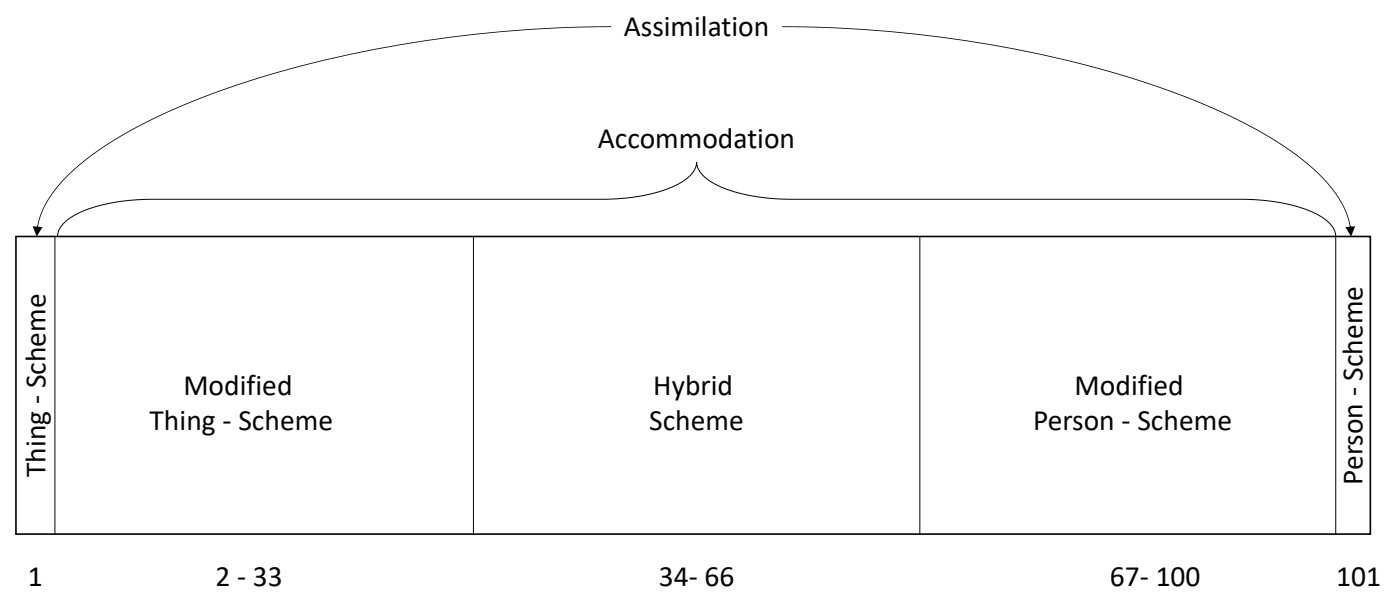

FIGURE 3 Equilibration on the Object-Subject Classification Scale (1 to 101), Etzrodt (2021)

Attributes of the situation were measured as previous knowledge of and interactions with the assigned VBA and the social contexts in which these interactions are usually embedded. Previous knowledge assessed if the participants had ever heard about or knew any VBAindependent of their assigned VBA. Previous interactions differentiate between participants who had contact with their assigned VBA for the first time through our survey or knew this VBA solely from fiction or non-fiction media, advertising, or had seen others using it, but had none or only minimal prior interactions, and those who had continuous previous interactions through ownership. Therefore, the first group can be assumed to have had none or only few equilibration processes before the study. In contrast, the latter group was likely to have had undergone this process several times. In addition, we considered the frequency of use on a 5-level rating scale from "very occasionally" to "very often." We assessed the social contexts of use by asking if participants usually used the VBA in multi-person contexts (family, friends, or acquaintances) or dyad contexts (the absence of other people). 
Attributes of the user were assessed by the user's personality, affinity for technology, and demographics such as age and gender. Personality was measured with the "Big Five Inventory" short scale using the original 5-level rating scale (Rammstedt et al., 2013). Principal component analysis (PCA) confirmed the factors agreeableness, conscientiousness, emotional stability, extraversion, culture (creativity) $\left(\chi^{2}(45)=1451.02, \mathrm{p}<.001, \mathrm{KMO}=.60\right.$, most factor loadings and $\mathrm{h} 2>.60$ ). "Agreeableness" exhibited the poorest performance and was interpreted with caution. Affinity for Technology was measured with nine items of the German ATI Scale (Franke et al., 2018), indexed into one component via PCA $\left(\chi^{2}(36)=\right.$ $5375.01, \mathrm{p}<.001, \mathrm{KMO}=.91$, Cronbach's alpha $=.92$, factor loadings $.63-.88 ; \mathrm{h} 2>.60)$. The PCAs in the staff sample confirmed these factors (see OSF).

Attributes of the Agent. Agency was conceptualized as an assigned capability to act, divided into the three dimensions: similarity to the behavior of the respondent ("Does not behave like me-behaves like me," 7-level rating scale), attributed attention of the respective VBA, and the feeling of interdependence. Subsequent operationalizations were realized either for Alexa or Google Assistant. For easier reading, only the Alexa variant is provided in the examples. The two latter dimensions were measured with five items based on the reduced relational communication scale by Ramirez (2009), using the original 6-level rating scale, but formulated for a hypothetical situation ("Imagine you and Alexa are having a conversation..."). However, the confirmatory factor analysis (CFA) indicated that these items loaded on the dimensions attention ("How attentive is Alexa to the interaction?", "How strongly is Alexa involved in an interaction?"), and interdependence ("How much is Alexa adapting to the interaction?", "How ready is Alexa to have an interaction with you?", "How strongly does Alexa respond to your comments or questions?") suggested by Biocca and colleagues (2003). To assess convergent validity, the standardized factor loadings, average variance extracted (AVE), and reliabilities (omega and Cronbach's alpha) were examined. The CFA showed both an excellent model fit for the dimensions $\left(\chi^{2}(4)=8.987\right.$, GFI $=.994$, $\mathrm{CFI}=.995, \mathrm{TLI}=.989, \mathrm{RMSEA}=.044)$ and a moderate convergent validity $(\mathrm{AVE}>.51$, omega $>.68$, Cronbach's alpha $>.66$ ), confirmed by the staff sample (see OSF).

Attributes of the Agent. Mind was operationalized as the VBA's similarity in thinking and feeling (e.g., "Thinks like me-does not think like me," 7-level rating scale), the VBA's ability to understand its user ("How well does Alexa understand you?", 7-level rating scale), and attributed personality traits. The modified Minimal Redundancy Scale based on Lang (2008) was used to measure the VBA's personality on a semantic differential using the original 6-level rating scale, indexed to the Big Five factors. However, not all human personality traits worked for the VBAs. CFA identified the items warmhearted, selfless, over-accurate, confident, self-contented, open, loving company, and inventive as insufficient. After their removal the model produced an excellent fit $\left(\chi^{2}(80)=227.330\right.$, GFI $=.964$, CFI $=.964$, $\mathrm{TLI}=.950, \mathrm{RMSEA}=.046$ ), a good reliability with most factor loadings larger than 0.7 , and a moderate convergent validity (AVE $>0.40$, omega $>0.50$ ), confirmed by the staff sample (see OSF). As a result, the factor culture includes items exclusively referring to creativity (creative, imaginable, artistic) and was interpreted accordingly. In line with previous research (Garcia et al., 2018; Guzman, 2020), participants had problems assigning emotions to the VBA explaining why the factor emotional stability displays the poorest performance. 
The factor was maintained for comparison with subsequent studies but was interpreted cautiously.

\section{Results}

Data was analyzed using R. In particular, the VBAs' classification and attributes showed non-normal, mainly positively skewed and heavy-tailed distributions. Thus, robust tests (packages WRS2, and robustbase) were used to control the results of common statistical tests. The stepwise robust regression found several outliers (with weights $=0$ or $\sim=1$ ). Although, the significance of the predictors was equal, the estimates differed slightly between OLS and robust regression. Thus, to avoid inaccuracy, we report the estimates of the robust regression. Reported results apply to the student sample and will be validated by the staff sample. The supplemental tables and figures can be found at this study's OSF repository.

\section{Equilibration of the Object-Subject Classification}

Almost one out of three participants assimilated VBAs into an existing scheme, while more than two out of three had accommodated their schemes (RQ1, Figure 4).

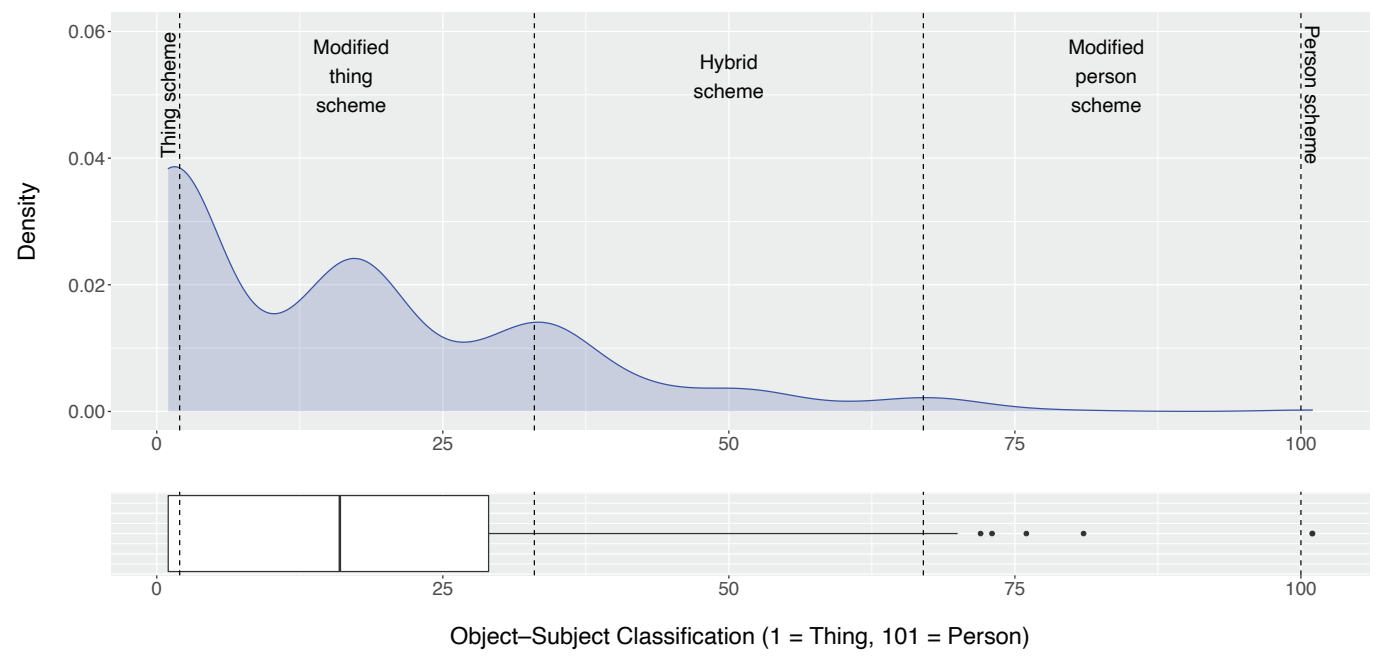

FIGURE 4 Density Plot and Box Plot, of the Equilibration on the Object-Subject Scale, Student Sample

As predicted ( $\mathrm{H} 1)$, in case people did assimilate, they almost always objectified VBAs (Table 1). In contrast, apart from two people, the VBAs were not subjectified at all. In case people accommodated, most of them classified the VBAs into modified schemes primarily with respect to the thing scheme $(49 \%$, Table 1$)$, whereas only a minimal number of people (2\%) modified the person scheme. Thus, VBAs were mainly classified as things supplemented by aspects of a person. However, 17\% classified the VBA into a hybridized scheme. 
TABLE 1 Equilibration of the VBA

\begin{tabular}{|l|l|c|c|c|c|}
\hline \multicolumn{2}{|c|}{} & Student Sample & \multicolumn{2}{c|}{ Staff Sample } \\
\cline { 3 - 6 } & Thing scheme & $n$ & $\%$ & $n$ & $\%$ \\
\hline \multirow{3}{*}{ Accommodation } & 263 & 31.0 & 141 & 32.7 \\
\cline { 2 - 6 } & Modified thing scheme & 419 & 49.4 & 208 & 48.3 \\
& Hybrid scheme & 148 & 17.4 & 67 & 15.6 \\
& Modified person scheme & 17 & 2.0 & 15 & 3.5 \\
\hline Assimilation & Person scheme & 2 & 0.2 & 0 & 0.0 \\
\hline Note: On a scale from 1 to 101, 1 = thing, 2 to 33 = modified thing scheme, 34 to 66 = hybrid \\
scheme, 67 to 100 $=$ modified person scheme, 101 = person scheme \\
\hline
\end{tabular}

Although most of the participants were quite certain with their classification $(M=4.34$, $\mathrm{SD}=0.89$ ), the further they moved away from the thing scheme, the more uncertain they became, $r=-.54, \mathrm{t}(842)=-18.56, \mathrm{p}<.001$. However, the LOESS graph (Figure 5) indicates that the uncertainty increases if the classification moves away from any existing scheme. Although very few people subjectified VBAs, they did it with the same level of certainty as those who objectified them. Consequently, modification and hybridization exhibited uncertainty.

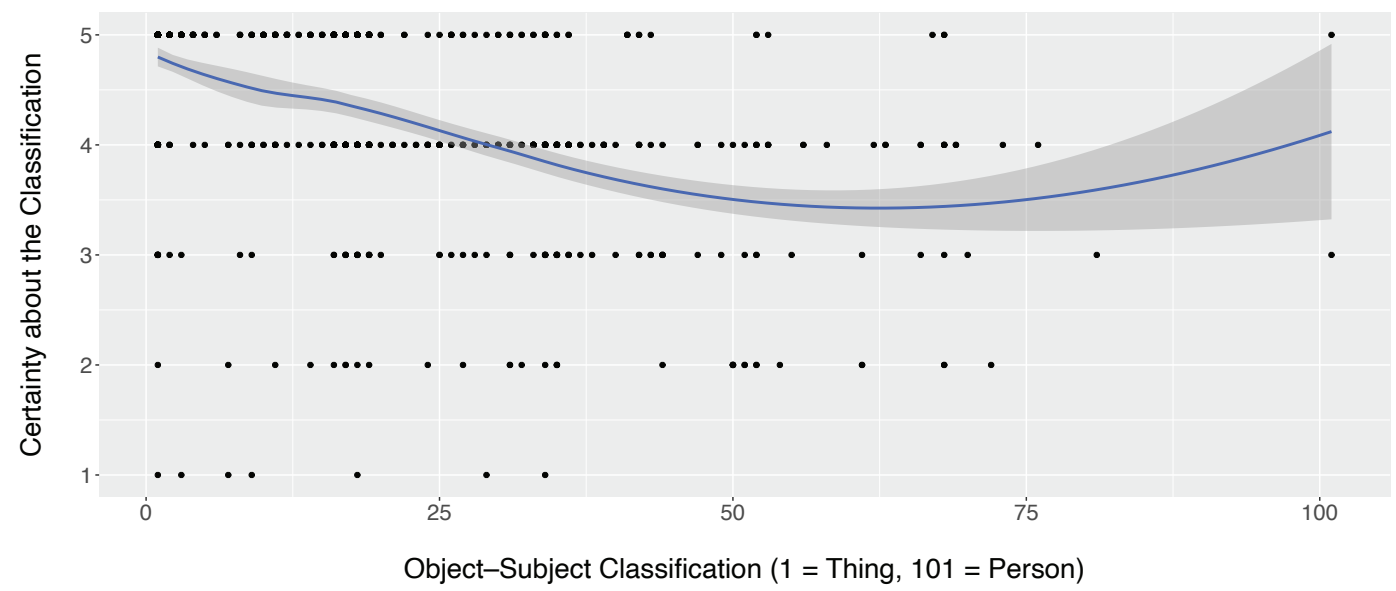

FIGURE 5 Classification Correlated With Certainty About the Classification, Student Sample

\section{Influences on the Object-Subject Classification}

To identify relevant influences on the classification (RQ2) we conducted a stepwise robust regression (SRR). The SRR indicated that more participants classified Alexa further away from the pole thing than Google Assistant if the previous experienced situations were held constant (Table 2, Model 2). However, the explained variance was low, and including the VBAs' agency eliminated this effect (Table 2, Models 4). 


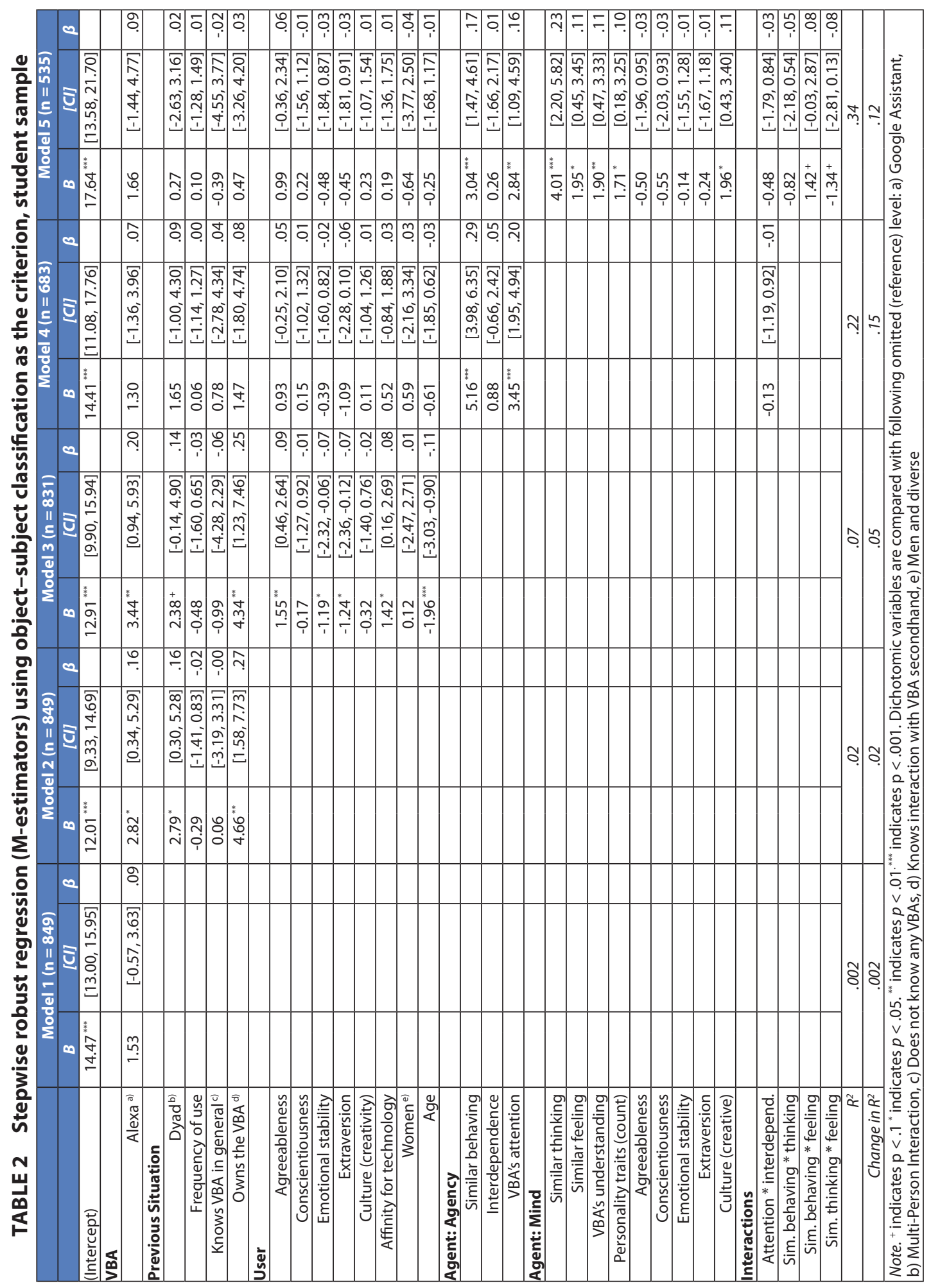


Attributes of the Situation. As predicted in H2, previous interactions affected the classification (Model 2, Table 2). If people owned the VBA they classified it more distanced from the pole thing than people who presumably equilibrated their classification for the first time. Contrary to our assumption (H3), the absence of other people increased the distancing from the mere thing scheme. However, the explained variance was still less than $1 \%$, and the effects disappeared after including the VBAs' agency (Table 2, Model 4).

Attributes of the User. As age increased, the classification tended toward the thing scheme (Table 2, Model 3). In contrast, people with more affinity for technology tended to distance from the mere thing scheme (Table 2, Model 3). In line with K. M. Lee \& Nass (2005) the gender of the user was not significant at all for the classification. However, personality traits were. Agreeable users were more inclined to classify the VBA distanced from the thing pole, while more emotionally stable and extraverted users exhibited objectification tendencies. Nevertheless, the explanatory power of the model remained small and the inclusion of the VBAs' attributes eliminated most effects. Whereas agency negated the effects of age, affinity for technology, emotional stability, and agreeableness (Table 2, Model 4) assumed mind negated the effects of extraversion (Table 2, Model 5).

Attributes of the Agent. Perceived agency contributed significantly to a classification distanced from the mere thing scheme and increased the explained variance to $22 \%$ (Table 2, Model 4). The VBAs' attentiveness $(\mathrm{M}=3.3, \mathrm{SD}=1.29)$ and interdependence $(\mathrm{M}=3.9$, $\mathrm{SD}=1.23$ ) were rated moderately high, whereas their behavior was not perceived as very similar $(\mathrm{M}=2.1, \mathrm{SD}=1.64)$. However, only increasing attentiveness and similar behavior increased a distanced classification from the pole thing. The effects held when mind attributes were added but weakened substantially.

Perceived mind increased the explained variance to 34\% (Table 2, Model 5). Although the similarity of mind was rated low, the VBAs' thinking $(\mathrm{M}=2.12, \mathrm{SD}=1.61)$ was assumed to be more similar than their feeling $(\mathrm{M}=1.60, \mathrm{SD}=1.61)$. Consistently, distancing of the thing scheme was predicted to a higher degree by similarity in thinking than in feeling (Table 2, Model 5). In contrast, the VBAs' ability to understand the user was rated moderately high $(\mathrm{M}=3.64, \mathrm{SD}=1.67)$ and also affected the distancing from the thing scheme to a similar amount. Participants assigned on average 16 out of 25 personality items to the VBAs $(M=16.5, S D=10.2)$. They were perceived as very conscientious $(M=4.9, S D=0.86)$, emotionally stable $(M=4.7, S D=0.97)$, agreeable $(M=4.6, S D=1.00)$, and extraverted $(\mathrm{M}=4.5, \mathrm{SD}=1.09)$ but less creative $(\mathrm{M}=3.0, \mathrm{SD}=1.33)$. Alexa was perceived as slightly more conscientious $(\mathrm{M}=5.1, \mathrm{SD}=0.77)$ than Google Assistant $(\mathrm{M}=4.7, \mathrm{SD}=0.91)$, $\mathrm{t}(644.34)=5.803, \mathrm{p}<.001$. However, only the number of personality items and the VBAs' creativity predicted a classification distanced from the mere thing scheme (Table 2, Model 5).

Mediation Analyses. Based on the indications of previous studies (e.g., Nass \& Lee, 2001; Woods et al., 2007), and because the VBAs' attributes eliminated the effects of the situations' and the users' attributes, we investigated whether mediation effects were involved. We focus on mediated variables that had a significant impact on the classification in Models 1 to 3, verified by the second sample (see below), and on mediating variables which were significantly affecting these. Results are reported in Table A2 (OSF). 
Alexa's classification increasingly distanced from the pole thing, due to a higher perceived capability of understanding the user compared to the Google Assistant. However, the explained variance is very low, thus the two agents do not differ very much from each other in this respect. Regarding the effect of the situation, both ownership and the previous use of the VBAs in the absence of others were mediated by agent attributes. Whereas ownership increased the VBAs' similarity in behaving and thinking and its attributed attentiveness, previous use in the absence of other people heightened all agency and mind attributes of the VBA (except similar feeling), encouraging a classification distanced from the thing scheme. User attributes exhibit mediation effects for age and extraversion, both increasing a classification toward the pole thing. Whereas increasing age lowered the attributed attention, number of personality items in general, and the VBAs' creativity, more extraverted users perceived less similarity in feeling and fewer personality items. Effects of matching the respondent's and VBA's personality indicated by previous findings (Nass \& Lee, 2001; Woods et al., 2007) could not be confirmed.

Based on the results of the stepwise robust regression and the mediation analysis, the theoretical model was adapted (see Figure A1 in the OSF).

\section{Validation of the Results by the Staff Sample}

In this section, we will focus on the most important commonalities and differences in relation to the student sample. The staff sample confirmed the VBAs' classification (Table 1), the amount of confidence $(\mathrm{M}=4.45, \mathrm{SD}=0.84)$ and its relation to the classification, $\mathrm{r}=-.48$, $\mathrm{t}(429)=-11.38, \mathrm{p}<.001$. The influences on the classification were partly confirmed (Table A3 in the OSF). Whereas, the impacts of age and extraversion (Model 3), the VBAs' similar behaving (Model 4) and thinking, its creativity, and the interaction of similar thinking and feeling (Model 5) were confirmed, the influences of Alexa (vs. Google Assistant), ownership and previous use in the absence of other people on the classification were not (Model 2). However, the direction of the ownership's and dyad's effect remained and-consistent with the student sample-mediating effects of the VBAs' attributes occurred, although some involved attributes differed (Table A4 in the OSF). The widespread impact of the previous dyadic use on the VBAs' attention, similar thinking and feeling, and creativity was strengthened; the impacts of the users' age through decreased attributed attention to the VBA and of the users' extraversion through decreased perceived similarity in feeling were confirmed.

\section{Discussion}

In this paper we analyzed how people classify their counterpart when they interact with voice-based agents and how attributes of the situation, the user, and the agent influence this classification. By referring to Piaget (1970/1974), we introduced an empirically measurable gradual ontological object-subject classification of VBAs, based on a 100-point scale ranging from thing to person, enabling the identification of the degree to which artificial agents are objects of doubt (Geser, 1989; Reeves \& Nass, 1996; Turkle, 1984/2005). Using the VBA as an example, we have demonstrated the potential of this scale, providing the basis for systematic investigations into how people classify various machines and how the classification is affected. 
Consistent with previous research (e.g., A. Edwards, 2018; Guzman, 2015), the majority of our participants could not definitely classify VBAs. The object-subject classification ranged between the two schemes thing ("what") and person ("who"), as predicted by Geser (1989) and Gunkel (2020). That is, most people were indeed in doubt. How people compensated for this doubt was analyzed through the concept of equilibration (Piaget, 1970/1974): Whereas some people had assimilated VBAs by objectifying, almost none had subjectified them. However, most people had accommodated their classification by modifying the thing scheme, and some even hybridized it, but still with a bias toward the thing scheme. That is, people reaffirmed their lines between things and persons (Turkle, 1984/2005, p. 34) by embedding VBA in the world of things, partly enriched with aspects of the person scheme. Hence, VBAs are personified things.

By understanding that people classify VBAs as personified things, counterintuitive findings (Gambino et al., 2020) can be interpreted more precisely. The thing aspect in the classification things and personified things, on the one hand, emphasized the VBA's artificiality (see Guzman, 2015), thus encourages the reference "it" (see Purington et al., 2017), or the separation of machines from humans and apes (see A. Edwards, 2018). The person aspect of personified things, on the other hand, emphasized the VBA's personhood, causing the simultaneous use of the pronouns "it" and "she" (Guzman, 2015; Purington et al., 2017) and the assignment of social machines to (living) beings (see A. Edwards, 2018). Whereas the aspect of personhood may cause social reactions toward artificial agents (see Appel et al., 2012; Horstmann et al., 2018), their dominant nature as things is likely to be responsible for rather timid, and normatively undesirable social reactions, such as insults or discourtesy (see Cercas Curry \& Rieser, 2018; C. Edwards et al., 2019).

However, the classification of personified things was characterized by high uncertainty. The further the participants moved away from the established thing or person scheme, the less confident they became about their classification. That is, classifying by assimilation is the easy way, it is the passive (habituated) assignment of an object to an existing scheme. Whereas accommodation-as an active cognitive process of reaffirming the boundaries of the schemes-is fraught with far more doubts. As a result, this classification of personified things is fragile and unstable and may change significantly in time-especially regarding further developments of the agents' abilities and their societal embedding. Further longitudinal research will be required.

How much VBAs were classified as personified things was-in accordance with previous research (e.g., A. Edwards, 2018; Moon et al., 2016; Nass \& Brave, 2005)—mainly affected by the perception of the agent's attributes of agency (behaves similarly, is attentive) and mind (thinks and feels similar, understands, has a vast personality, especially a creative one). However, for the same effect on the classification, it required a much lower degree of mind than agency. Hence, "personified things" expands "social things" (Guzman, 2015) by implying abilities associated with personhood-even if their degree is low (Hubbard, 2011).

However, attributes of the situation and the user did indirectly alter the classification by affecting the VBAs' assumed agency and mind. In accordance with prior research (A. Edwards et al., 2019; Leite et al., 2013), previous regular interactions positively affected the perception of VBAs as personified things. In contrast to previous studies (e.g., Purington et al., 2017), the main use of VBAs in the dyad situation (i.e., in the absence of others) caused a stronger classification toward personified things, through increased perceived 
agency and mind. One explanation for this may be that the dyad fosters a more intense experience and lacks the "blueprint" of a human being. As a result, the users can engage more effectively with the VBA but have only themselves for comparison to project subjectivity. The effect found by Purington et al. may be caused by different dynamics. Thus, we encourage to further explore the dynamics of dyadic and multi-person environments regarding the classification.

Corresponding with Piaget (1970/1974), age was a crucial factor for subjectification by altering the VBA's agency and mind (e.g., Woods et al., 2007): The younger the participants, the more attentive, creative, and substantial in personality the VBAs were perceived to be. An essential factor in this respect is the continually increasing experience with objects of the environment, which gradually complement the classification and thus extend the options for comparison of included objects in the scheme.

Rather than an effect of matching personalities of the user and the VBA (Nass \& Lee, 2001), the findings were more ambiguous. Although VBAs were seen as very extraverted across subgroups, introvert people subjectified them more often, through increased perception of similarity in feeling and personality items in general. That is, introverts perceived a richer personality and emotionality in VBAs. Again, this phenomenon can be related to the above-mentioned projection of the users' experienced own subjectivity (Piaget, 1970/1974). As introverts may experience themselves as rich in emotion and personality, even though they are-compared to extroverts-less inclined to express these qualities to others, they likely attribute the same intensity of feelings and personality to the weak expressions of the VBAs.

As with all research, this study has several limitations, of which its hypothetical interaction with its pre-defined questions and answers is one. Additional studies need to validate the VBA's classification in real interactions and with different contents. A second limitation is the paper's focus on VBAs. Comparing various evocative technologies may allow a more distinct classification and may reveal differences in influencing attributes. Third, the classification of an object is the result of a dynamic equilibration process (Piaget, 1970/1974). Hence, we solely examined a snapshot of the process, not the process itself. However, it is unclear whether the classification resulted from initial or multiple equilibration processes. Most of the participants had at least some experience with the VBA, indicating potential prior equilibrations. Further research on the process itself, concerning initial and repeated equilibrations, influences, and related classifications, is needed.

To conclude, human-machine communication in the context of voice-based agents indicates that people communicate with personified things defined by a moderate agency and a basic mind. The more VBAs behave, think, feel similar, are perceived to be attentive to, and understand their users, and are at least to some extent creative, the more they are classified as personified things. Although this requires a moderate agency, a rather limited mind is sufficient. Depending on the opportunities for comparison on different levels, the classification is more or less hybrid. Comparisons take place on an individual (age, personality) and situational level (dyad). Age relates to the amount of experience with comparable evocative objects, users' personality relates to the comparison with their own behavior and mind, and the dyadic situation relates to the comparison with another human subject. However, the classification of VBAs as personified things is still fragile and they remain objects of doubt. 


\section{Author Biographies}

Katrin Etzrodt (MA) is a research assistant and PhD student at the Chair of Science and Technology Communication at the Technical University Dresden. From 2017 to 2020 she was granted a scholarship of the Program for the Promotion of Early-Career Female Scientists of TU Dresden.

(D) https://orcid.org/0000-0001-6515-9985

Sven Engesser $(\mathrm{PhD})$ is a Professor of Science and Technology Communication at the Technical University Dresden.

(D) https://orcid.org/0000-0003-1638-7548

\section{Acknowledgments}

The authors would like to thank the reviewers and the editorial team, whose suggestions have considerably improved the paper. Additionally, the authors would like to thank Lisa Weidmüller for her input and feedback at different stages of development. Ms. Etzrodt gratefully acknowledges the support and generosity of the Scholarship Program for the Promotion of Early-Career Female Scientists of TU Dresden, without which the present paper would not have been possible.

The supplemental material can be obtained from the study's Open Science Framework (OSF) repository: https://doi.org/10.17605/OSF.IO/5UNS2

\section{References}

Appel, J., von der Pütten, A., Krämer, N. C., \& Gratch, J. (2012). Does humanity matter? Analyzing the importance of social cues and perceived agency of a computer system for the emergence of social reactions during human-computer interaction. Advances in Human-Computer Interaction. https://doi.org/10.1155/2012/324694

Attig, C., Wessel, D., \& Franke, T. (2017, July 9-14). Assessing personality differences in human-technology interaction: An overview of key self-report scales to predict successful interaction. Proceedings of HCI International, Vancouver, BC, Canada. https://doi. org/10.1007/978-3-319-58750-9_3

Biocca, F., Harms, C., \& Burgoon, J. (2003). Towards a more robust theory and measure of social presence: Review and suggested criteria. Presence, 12, 456-480. https://doi. org/10.1162/105474603322761270

Broadbent, E. (2017). Interactions with robots: The truths we reveal about ourselves. Annual Review of Psychology, 68(1), 627-652. https://doi.org/10.1146/annurevpsych-010416-043958

Burgoon, J. K., Bonito, J. A., Bengtsson, B., Ramirez, Jr., A., Dunbar, N. E., \& Miczo, N. (1999). Testing the interactivity model: Communication processes, partner assessments, and the quality of collaborative work. Journal of Management Information Systems, 13(6), 33-56. https://doi.org/10.1080/07421222.1999.11518255 
Buss, D. M. (2008). Human nature and individual differences. Evolution of human personality. In O. P. John, R. W. Robins, \& L. A. Pervin (Eds.), Handbook of personality. Theory and research (3rd ed., pp. 29-60). The Guilford Press.

Cercas Curry, A., \& Rieser, V. (2018, June). \#MeToo Alexa: How conversational systems respond to sexual harassment. Proceedings of ACL Workshop on Ethics in Natural Language Processing. https://doi.org/10.18653/v1/W18-0802

Dimock, M. (2019). Defining generations: Where Millennials end and Generation Z begins. Pew Research Center. http://tony-silva.com/eslefl/miscstudent/downloadpagearticles/ defgenerations-pew.pdf

Edwards, A. (2018). Animals, humans, and machines: Interactive implications of ontological classification. In A. L. Guzman (Ed.), Human-machine communication: Rethinking communication, technology, and ourselves (pp. 29-49). Peter Lang.

Edwards, A., Edwards, C., Westerman, D., \& Spence, P. R. (2019). Initial expectations, interactions, and beyond with social robots. Computers in Human Behavior, 90, 308-314. https://doi.org/10.1016/j.chb.2018.08.042

Edwards, A., Westerman, D., Edwards, C., \& Spence, P. R. (2020). Communication is . . transhuman. In A. Tyma \& A. Edwards (Eds.), Communication is ... Perspectives on theory (pp. 49-66). Cognella Academic Publishing.

Edwards, C., Edwards, A., Stoll, B., Lin, X., \& Massey, N. (2019). Evaluations of an artificial intelligence instructor's voice: Social identity theory in human-robot interactions. Computers in Human Behavior, 90, 357-362. https://doi.org/10.1016/j.chb.2018.08.027

Epley, N., Waytz, A., \& Cacioppo, J. T. (2007). On seeing human: A three-factor theory of anthropomorphism. Psychological Review, 114(4), 864-886. https://doi. org/10.1037/0033-295X.114.4.864

Etzrodt, K. (2021). The ontological classification of conversational agents. An adaptation of Piaget's equilibration theory. In A. Følstad, T. Araujo, S. Papadopoulos, E. L.-C. Law, E. Luger, M. Goodwin, \& P. B. Brandtzaeg (Eds.), CONVERSATIONS 2020-4th International Workshop on Chatbot Research. Lecture Notes in Computer Science. Springer.

Franke, T., Attig, C., \& Wessel, D. (2018). A personal resource for technology interaction: Development and validation of the affinity for technology interaction (ATI) scale. International Journal of Human-Computer Interaction, 35(6), 456-467. https://doi.org/10.10 80/10447318.2018.1456150

Gambino, A., Fox, J., \& Ratan, R. A. (2020). Building a stronger CASA: Extending the computers are social actors paradigm. Human-Machine Communication, 1, 71-85. https:// doi.org/10.30658/hmc.1.5

Garcia, D. M. P., Lopez, S. S., \& Donis, H. (2018, July). Voice activated virtual assistants personality perceptions and desires: Comparing personality evaluation frameworks. Proceedings of International BCS Human Computer Interaction Conference, Swindon United Kingdom. https://doi.org/10.14236/ewic/HCI2018.40

Geser, H. (1989). Der PC als Interaktionspartner [The PC as interaction partner]. Zeitschrift für Soziologie, 18(3), 230-243. https://doi.org/10.1515/zfsoz-1989-0305

Guadagno, R. E., Blascovich, J., Bailenson, J. N., \& McCall, C. (2007). Virtual humans and persuasion: The effects of agency and behavioral realism. Media Psychology, 10(1),1-22. Gunkel, D. J. (2020). An introduction to communication and artificial intelligence. Wiley. 
Guzman, A. L. (2015). Imagining the voice in the machine: The ontology of digital social agents [PhD Thesis]. University of Illinois at Chicago.

Guzman, A. L. (2018). What is human-machine communication, anyway? In A. L. Guzman (Ed.), Human-machine communication: Rethinking communication, technology, and ourselves (pp. 1-28). Peter Lang. https://doi.org/10.3726/b14399

Guzman, A. L. (2019). Voices in and of the machine: Source orientation toward mobile virtual assistants. Computers in Human Behavior, 90, 343-350. https://doi.org/10.1016/j. chb.2018.08.009

Guzman, A. L. (2020). Ontological boundaries between humans and computers and the implications for Human-Machine Communication. Human-Machine Communication, 1, 37-54. https://doi.org/10.30658/hmc.1.3

Higgins, E. T., \& Scholer, A. A. (2008). When is personality revealed? A motivated cognition approach. In O. P. John, R. W. Robins, \& L. A. Pervin (Eds.), Handbook of Personality. Theory and Research (3rd ed., pp. 128-207). The Guilford Press.

Horstmann, A. C., Bock, N., Linhuber, E., Szczuka, J. M., Straßmann, C., \& Krämer, N. C. (2018). Do a robot's social skills and its objection discourage interactants from switching the robot off? PLoS ONE, 13(7): e0201581. https://doi.org/10.1371/journal.pone.0201581

Hubbard, F. P. (2011). "Do androids dream?": Personhood and intelligent artifacts. Temple Law Review, 83, 405-474. https://ssrn.com/abstract=1725983

Knorr-Cetina, K. D. (2001). Objectual practice. In T. R. Schatzki (Ed.), The practice turn in contemporary theory (pp. 175-188). Routledge, London.

Krummheuer, A. (2015). Technical agency in practice: The enactment of artefacts as conversation partners, actants and opponents. PsychNology Journal, 13, 179-202. http://www.psychnology.org/File/PNJ13\%282-3\%29/PSYCHNOLOGY_JOURNAL_13_2_ KRUMMHEUER.pdf

Lang, D. S. (2008). Soziale Kompetenz und Persönlichkeit. Zusammenhänge zwischen sozialer Kompetenz und den Big Five der Persönlichkeit bei jungen Erwachsenen [Social competence and personality. Correlations between social competence and the Big Five of personality in young adults] [PhD Thesis]. Universität Koblenz-Landau. https:// kola.opus.hbz-nrw.de/opus45-kola/frontdoor/deliver/index/docld/264/file/Soziale KompetenzundPersoenlichkeit.pdf

Latour, B. (1995). Wir sind nie modern gewesen. Versuch einer symmetrischen Anthropologie [We have never been modern]. Suhrkamp. (Original work published 1991.)

Latour, B. (2005). Reassembling the social. An introduction to Actor-Network-Theory (ANT). Oxford.

Lee, E. J. (2008). Flattery may get computers somewhere, sometimes: The moderating role of output modality, computer gender, and user gender. International Journal of Human-Computer Studies, 66(11), 789-800. https://doi.org/10.1016/j.ijhcs.2008.07.009

Lee, E. J., Nass, C., \& Brave, S. (2000, April). Can computer-generated speech have gender? An experimental test of gender stereotype. Proceedings of $\mathrm{CHI}$ on Human Factors in Computing Systems, the Hague the Netherlands. https://doi.org/10.1145/633292.633461 Lee, K. M. (2004). Presence, explicated. Communication Theory, 14(1), 27-50. https://doi. org/10.1111/j.1468-2885.2004.tb00302.x 
Lee, K. M., \& Nass, C. (2005). Social-psychological origins of feelings of presence: Creating social presence with machine-generated voices. Media Psychology, 7(1), 31-45. https:// doi.org/10.1207/S1532785XMEP0701_2

Leite, I., Martinho, C., \& Paiva, A. (2013). Social robots for long-term interaction: A survey. International Journal of Social Robotics 5, 291-308. https://doi.org/10.1007/s12369-0130178-y

Lombard, M., Lee, S., Sun, W., Xu, K., \& Yang, H. (2017). Presence theory. In P. Rössler, C. A. Hoffner, \& L. van Zoonen (Eds.), The international encyclopedia of media effects (pp. 1-13). John Wiley \& Sons Inc. https://doi.org/10.1002/9781118783764.wbieme0087

Lopatovska, I., \& Williams, H. (2018, March 11-15). Personification of the Amazon Alexa: $B F F$ or a mindless companion? Proceedings of the ACM CHIIR Conference, New Brunswick. https://doi.org/10.1145/3176349.3176868

Moon, Y., Kim, K. J., \& Shin, D.-H. (2016, July 17-22). Voices of the Internet of Things: An exploration of multiple voice effects in smart homes. In P. M. Norbert Streitz (Ed.), Proceedings of the DAPI Conference held as part of HCI International, Toronto, Canada. https://doi.org/10.1007/978-3-319-39862-4

Nass, C., \& Brave, S. (2005). Wired for speech-How voice activates and advances the human-computer relationship. MIT Press.

Nass, C., \& Lee, K.-M. (2001). Does computer-generated speech manifest personality? Experimental test of recognition, similarity-attraction, and consistency-attraction. Journal of Experimental Psychology: Applied, 7(3), https://doi.org/10.1037/1076-898X.7.3.171

Nass, C., \& Moon, Y. (2000). Machines and mindlessness: Social responses to computers. Journal of Social Issues, 56(1), 88-103. https://doi.org/10.1111/0022-4537.00153

Nass, C., Steuer, J., \& Tauber, E. R. (1994). Computers are social actors. Proceedings of CHI Conference on Human Factors in Computing Systems, Boston Massachusetts USA. https://doi.org/10.1145/191666.191703

Newman, N. (2018). Digital news project. The future of the voice and the implications of news. Reuters Institute for the Study of Journalism \& University of Oxford. https://reuters institute.politics.ox.ac.uk/our-research/future-voice-and-implications-news

Piaget, J. (1974). Abriß der genetischen Epistemologie [The principles of genetic epistemology] (F. Kubli, Trans.). Walter-Verlag AG Olten. (Original work published 1970.)

Premack, D., \& Woodruff, G. (1978). Does the chimpanzee have a theory of mind? Behavioral and Brain Sciences, 1(4), 515-526. https://doi.org/10.1017/S0140525X00076512

Purington, A., Taft, J. G., Sannon, S., Bazarova, N. N., \& Taylor, S. H. (2017, May). "Alexa is my new BFF": Social roles, user satisfaction, and personification of the Amazon Echo. CHI'17 Extended Abstracts. https://doi.org/10.1145/3027063.3053246

Ramirez Jr., A. (2009). The effect of interactivity on initial interactions: The influence of information seeking role on computer-mediated interaction. Western Journal of Communication, 73(3), 300-325. https://doi.org/10.1080/10570310903082040

Rammstedt, B., Kemper, C. J., Klein, M. C., Beierlein, C., \& Kovaleva, A. (2013). A short scale for assessing the big five dimensions of personality: 10 item big five inventory (BFI10). Methoden, Daten, Analysen, 7(2), 233-249. https://doi.org/10.12758/mda.2013.013

Ray, G. B. (1986). Vocally cued personality prototypes: An implicit personality theory approach. Communication Monographs, 53(3), 266-276. https://doi. org/10.1080/03637758609376141 
Reeves, B., \& Nass, C. I. (1996). The media equation: How people treat computers, television, and new media like real people and places. Cambridge University Press.

Reichertz, J. (2014). Von Menschen und Dingen. Wer handelt hier eigentlich [Of people and things. Who is actually acting]? In A. Poferl \& N. Schröer, (Eds.), Wer oder was handelt? Zum Subjektverständnis der hermeneutischen Wissenssoziologie, 95-120. Springer Fachmedien. https://doi.org/10.1007/978-3-658-02521-2

Roßler, G. (2008). Kleine Galerie neuer Dingbegriffe: Hybriden, Quasi-Objekte, Grenzobjekte, epistemische Dinge [Small gallery of new terms: hybrids, quasi-objects, boundary objects, epistemic things]. In G. Knef, M. Schröer, \& E. Schüttpelz (Eds.), Bruno Latours Kollektive (pp. 76-107). Suhrkamp.

Schütz, A. (1974). Der sinnhafte Aufbau der sozialen Welt: Eine Einleitung in die verstehende Soziologie [The phenomenology of the social world: An introduction into verstehende sociology]. Suhrkamp, Frankfurt.

Short, J., Williams, E., \& Christie, B. (1976). The social psychology of telecommunications. Wiley.

Simmel, G. (1908). Soziologie Untersuchungen über die Formen der Vergesellschaftung [Inquiries into the construction of social forms]. Duncker \& Humbolt.

Singh, A. (2014). Challenges and issues of Generation Z. In Journal of Business and Management, 16(7), 59-63. https://pdfs.semanticscholar.org/b109/73a5c6d11f37542adc34455 bb0c7fbcbbb9d.pdf

Suchman, L. (2011). Subject objects. Feminist Theory, 12(2), 119-145. https://doi. org/10.1177/1464700111404205

Turing, A. M. (1950). Computing machinery and intelligence. Mind, 59(236), 433-460. https://www.jstor.org/stable/2251299

Turkle, S. (2005). The second self (Twentieth anniversary edition). The MIT Press. (First edition published by Simon \& Schuster, Inc., New York, 1984). https://doi.org/10.7551/ mitpress/6115.001.0001

Weber, M. (1922). Wirtschaft und Gesellschaft [Economy and society]. Mohr, Tübingen.

Woods, S., Dautenhahn, K., Kaouri, C., te Boekhorst, R., \& Koay, K. L. (2007). Is this robot like me? Links between human and robot personality traits. Interaction Studies, $8(2)$, 281-305. https://doi.org/10.1075/is.8.2.06woo 

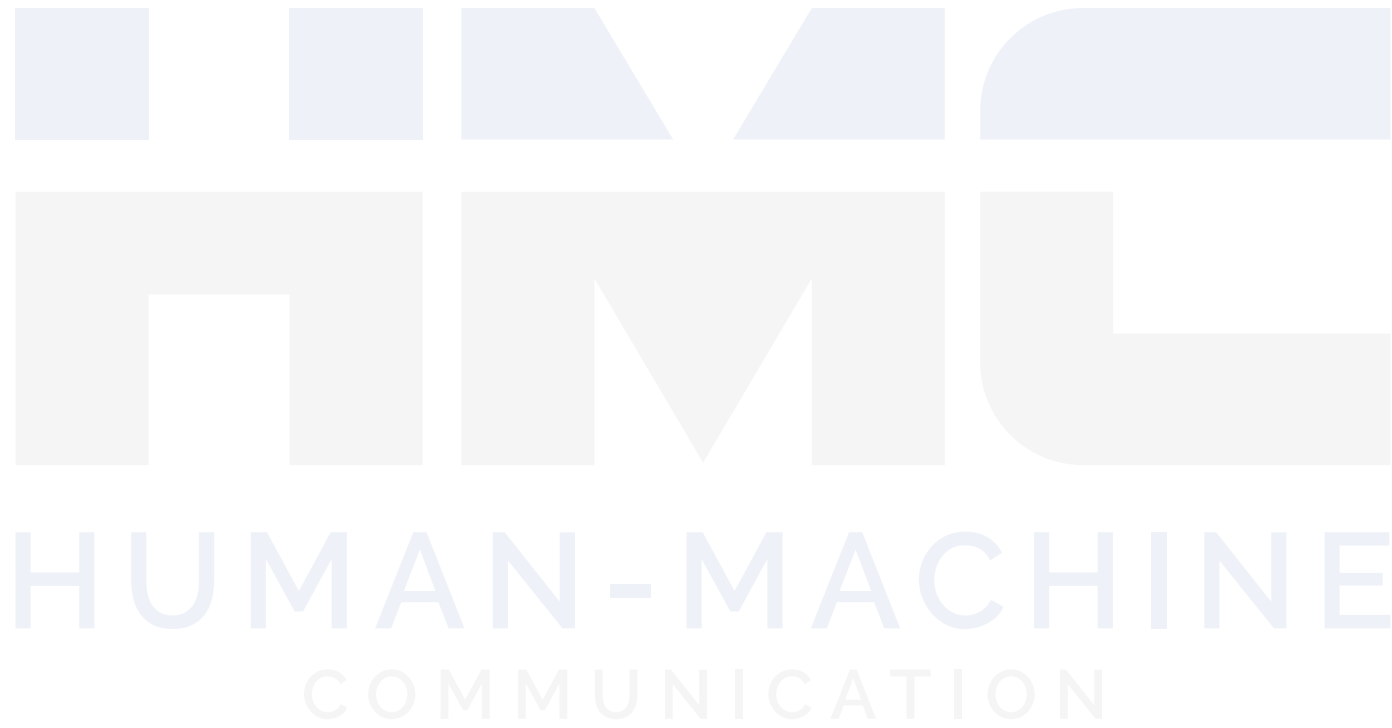